\title{
Sequential scheelite mineralization of Sangdong W-deposit, South Korea: microtextural evidence
}

\author{
WoOhyun ChOI ${ }^{1}$, YUngOo SONG $^{1 *}$, CHANGYUn PARK ${ }^{2}$, \\ CHULKYOO LEE ${ }^{1}$ \\ ${ }^{1}$ Yonsei Univ. BK21+ institute of Earth. Atmosphere. \\ Astronomy, Seoul, Korea \\ ${ }^{2}$ Korea Institute of Geoscience and Mineral Resources, \\ Pohang, Korea \\ (*correspondence: yungoo@yonsei.ac.kr)
}

The Sangdong W-deposit is known as one of the world's largest tungsten ore deposits, which is located in Taebaeksan mineralizaed district of South Korea.

The hangingwall orebody is hosted within the Pungchon limestone formation, whereas the main and footwall orebodies are hosted within interbedded limestone layers in the Myobong slate formation. Age of the deposit was known as about $87 \mathrm{Ma}$, the late Cretaceous period. Orebodies can be divided into the proximal pyroxene-garnet skarn zone with low scheelite content, and the hydrothermal alteration zone (quartz-mica and quartz-amphibole alteration zones) with relatively abundant scheelite. The hydrothermal alteration occurred typically in the retrograde stage, which is the main mineralization process to precipitate scheelite. In this stage the various types of quartz vein (layered, cross-cut, dendritic, etc.) formed as different width, in which scheelite was disseminated as micro- to mm-sized subhedral to anhedral forms with almost pure $\mathrm{CaWO}_{4}$ composition. Small amounts of native bismuth and bismuth sulfide were co-precipitated with scheelite, indicating the evidence of W-Bi mineralization. Scheelite precipitation was followed by amphibole/bioite, or chlorite, probably due to the difference in temperature of hydrothermal fluid, in the later stage. As subsequent alteration being continued, typical mineral assemblages of muscovite - calcite - Fe-sulfide - fluorite - laumontite were associated with scheelite as filling texture, with decreasing temperature of mineralizing fluid.

Keyword: Sangdong W-deposit, scheelite, microtexture 